\title{
THERMODYNAMIC ANALYSIS OF VAPOUR ABSORPTION REFRIGERATION SYSTEM USING SOLAR ENERGY
}

\author{
V.Srikanth ${ }^{1}$, B.Raja Narender ${ }^{2}$ and Dr.AVSSKS Gupta ${ }^{3}$
}

\begin{abstract}
A binary mixture of ammonia-water is used as working fluid. When the mixture gets heat more volatile ammonia vaporizing first and then water starts vaporizing. In the present work, firstly property data for ammonia and ammonia water mixture are calculated from the equation developed based on the first law of thermodynamics to obtain the specific enthalpy, specific entropy and specific volume. C program was developed to calculated specific enthalpy, specific entropy and specific volume of ammonia and ammonia water mixture at a given temperature, pressure and concentration. The thermodynamic analysis of ammonia water is done. Solar based vapour absorption refrigeration cycle is identified. The key parameters which influence the cycle performance such as generator inlet and evaporator temperatures are studied. The current analysis results indicate that, the COP of cycle slightly decreases by varying the concentration of ammonia at constant generator temperature and pressure. The slight decrease in COP could be because of increasing the concentration of ammonia, the properties of ammonia i.e., enthalpy at generator exit increases resulting in increase in work input. Similarly with increase in pressure work input increase at generator, thus reducing the COP . As the pressure increases with concentration of ammonia kept at constant, the enthalpy at the generator increases resulting in increase in generator heat input. Hence as pressure increases COP decreases.
\end{abstract}

Keywords: Solar Aborption, Ammonia-Water mixture,Thermodynamic analysis.

\section{INTRODUCTION}

In2002, Shaoguang Lu and D. Yogi Goswami[2] A new combined power/refrigeration cycle use ammonia/water mixture as a working fluid to produce both power and refrigeration in the same cycle. The cycle may be designed for various combinations of power and refrigeration. In an earlier paper by the authors, the cycle was optimized for efficiency, with power as the main intended output. This study puts an emphasis on the refrigeration part of the total output especially at low refrigeration temperatures. The objective was to find out what kind of outputs could be obtained at very low temperatures for a possible application in the Mars mission. The thermal performance of this cycle at different refrigeration temperatures has been found. At each refrigeration temperature, the cycle is optimized for maximum second law efficiency using Generalized Reduced Gradient (GRG) algorithm. It is found that refrigeration temperatures as low as $205 \mathrm{~K}$ may be achieved using this cycle. Generally, both first and second law efficiencies

\footnotetext{
${ }^{1}$ Department of Mechanical Engineering,Anurag Group of Institutions, CVSR College of Engineering,Venkatapur,GhatkesarR.R.Dist,Telangana, India

${ }^{2}$ Department of Mechanical Engineering,Anurag Group of Institutions, CVSR College of Engineering,Venkatapur,GhatkesarR.R.Dist,Telangana, India

${ }^{3}$ Department of Mechanical Engineering,JNTU,Hyderabad,Telangana,India
} 
decrease when refrigeration temperature drops. For a re-circulating type of solar thermal system with a source temperature of $360 \mathrm{~K}$, the first and second law efficiencies increase slightly as the refrigeration temperature goes down from $265 \mathrm{~K}$ to $245 \mathrm{~K}$ and then decrease with the refrigeration temperature, giving a maximum second law efficiency of $63.7 \%$ at $245 \mathrm{~K}$.

In 2007,Omer Kaynakli and Recep Yamankaradeniz[4] In this study, the first and law thermodynamic analysis of a single-stage absorption refrigeration cycle with water/lithium bromide as working fluid pair is performed. Thermodynamic Properties of each point in the cycle are calculated using related equations of state. Heat Transfer rate of each component in the cycle and some performance parameters are calculated from the first law analysis. From the second law analysis, the entropy generation of each component(S) and the total entropy generation of all the system components are obtained. Variation of the performance and entropy generation of the system are examined at various operating conditions. The Results show that high coefficient of performance (COP) Value is obtained at high generator and evaporator temperatures, and also at low condenser and absorber temperatures. With increasing generator temperature, total entropy generation of the system decreases. Whereas Maximum entropy generation occurs in the generator at various operating conditions, entropy generation in the refrigerant heat exchanger, expansion valve and solution pump is negligibly small.

In 2011, Satish Raghuvanshi and Go Maheshwari[5] The continuous increase in the cost and demand for energy has led to more research and development to utilize available energy resources efficiently by minimizing waste energy. Absorption refrigeration systems increasingly attract research interests. Absorption cooling offers the possibility of using heat to provide cooling. For this purpose heat from conventional boiler can be used or waste heat and solar energy. Absorption system falls into two categories depending upon the working fluid. These are the $\mathrm{LiBr}-\mathrm{H} 2 \mathrm{O}$ andNH3-H2O Absorption Refrigeration system. In $\mathrm{LiBr}-\mathrm{H} 2 \mathrm{O}$ system water is used as a refrigerant and $\mathrm{LiBr}$ is used as an absorbent, while in $\mathrm{NH} 3-\mathrm{H} 2 \mathrm{O}$ system ammonia used as an refrigerant and water is used as an absorbent, which served as standard for comparison in studying and developing new cycles and new absorbent/refrigerant pairs.

In 2012, V.Mariappan, M.Udayakumar, Pratisthit Lal Shrestha and S.Suresh[6] This study primarily focuses on the thermodynamic analysis of single stage vapor absorption refrigeration system using R134a -DMAC solution as the working fluid. Variations in the performance parameters of the system are studied against various operating temperatures of generator and absorber. The result of this theoretical study show that coefficient of performance (COP) value can be improved by elevating generator temperature up to certain level and lowering absorber temperature. At such elevated generator temperature, value of circulation ratio (CR) is lowered. The scope of this study is limited to the system with $1 \mathrm{~kW}$ evaporator capacity and effectiveness of solution heat exchanger (SHX) as 0.8. For the proposed condition of source and sink temperature $120^{\circ} \mathrm{C}$ and $40^{\circ} \mathrm{C}$ respectively the maximum value of COP was found to be 0.41 and corresponding $\mathrm{CR}$ value as 3.90.

\section{Literature available on $\mathrm{NH}_{3}-\mathrm{H}_{2} \mathrm{O}$ mixture properties}

Development of ammonia -mixture property data is the most important task for the analysis of the vapour absorption refrigeration cycle.

For ammonia-water mixture, to calculate the thermodynamic properties like specific enthalpy, specific entropy and specific volume, the need of bubble and dew point temperatures at various pressures and compositions are very essential and is the prior step. For estimating those temperatures, various correlations have been developed. 
The correlation developed by Patek and Klomfar in 1995 [7] is proposed in this work which avoids tedious iterations required. Ziegler and Trepp in 1984[18] described an equation for the thermodynamic properties of ammonia-water mixture in absorption units. In his work, the Gibbs excess energy equation was utilized for determining the specific enthalpy, specific entropy and specific volume. They developed the properties up to a pressure of 50 bar and temperature of 500 K.

Barhoumi et al. in 2004[8] presents modeling of the thermodynamic properties. Feng and Yogi in 1999] combine the Gibbs free energy method for mixture properties and the bubble and dew point temperature equations for phase equilibrium were used. Senthil and Subbarao in 2008 present fast calculation for determining enthalpy and entropy of the mixtures.

N.Shankar Ganesh and T.Srinivas in 2011[9] combined the correlations proposed by Ziegler et al. (1984) and carried out in MatLab, which avoids numerous procedure and time interval in obtaining the result. This can be used for energy and exergy solutions to power generating systems.

\section{OBJECTIVES OF THE WORK}

The main objectives of the present work are

- To develop a mathematical code for thermodynamic properties like specific enthalpy, specific entropy and Specific volume for ammonia-water mixture.

- $\quad$ To identify the solar based vapor absorption refrigeration cycle and its analysis.

- $\quad$ To analyze the effect of operating key parameters on the performance of the cycle.

To study the effect of ammonia concentration and generator pressure.

Using correlations developed by Patek and Klomfar [7]the bubble point and dew point temperatures at various pressures and concentrations are estimated. Using these equations a computer program is written in" $C$ " and developed graph at various pressures. The graph is shown below is up to pressure 50bar.
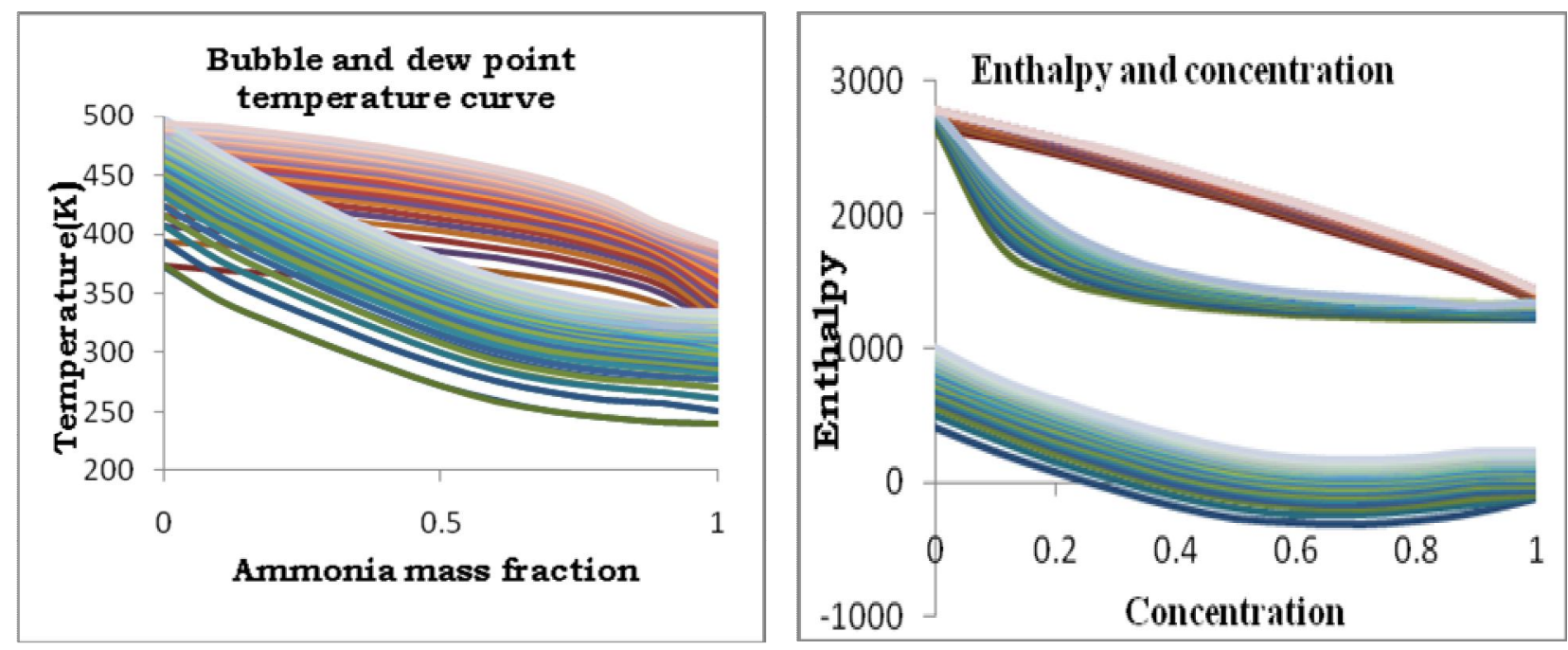

Fig.1 : Bubble and dew point temperatures

Fig.2:Ammonia-Water enthalpy concentration diagram

Fig. 1 shows the bubble and dew point temperatures developed with the correlation by Patek and Klomfar [7] up to pressure of 50 bar using 'C'code. 
Normally, charts of enthalpy-temperature-mass fraction are available which give both liquid phase as well as vapour enthalpy of mixtures. Fig.2 shows one such chart which shows the enthalpy-composition diagram at a constant pressure $\mathrm{P}$.

It is important to note that it is not possible to fix the state of the mixture (sub cooled, saturated, two-phase or superheated) just from temperature and mass fraction alone, though one can calculate enthalpy of the mixture from temperature and mass fraction. This is due to the reason that at a given mass fraction and temperature, depending upon the pressure the point can be sub cooled or saturated or superheated.

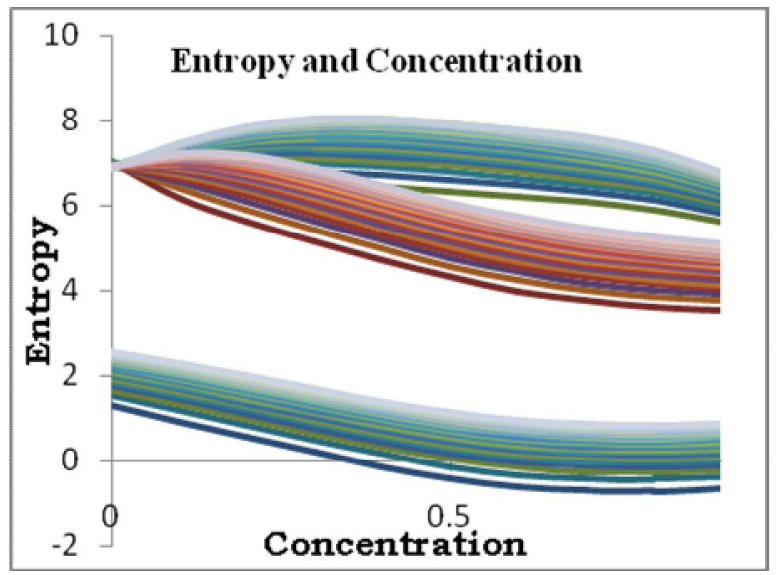

Fig.3: Ammonia-Water entropy concentration diagram

Fig.3 shows one such chart which shows the enthalpy-concentration diagram at a constant pressure $\mathrm{P}$.

\section{II.SOLAR BASED VAPOUR ABSORPTION REFRIGERATION CYCLE AND ITS THERMODYNAMIC ANALYSIS}

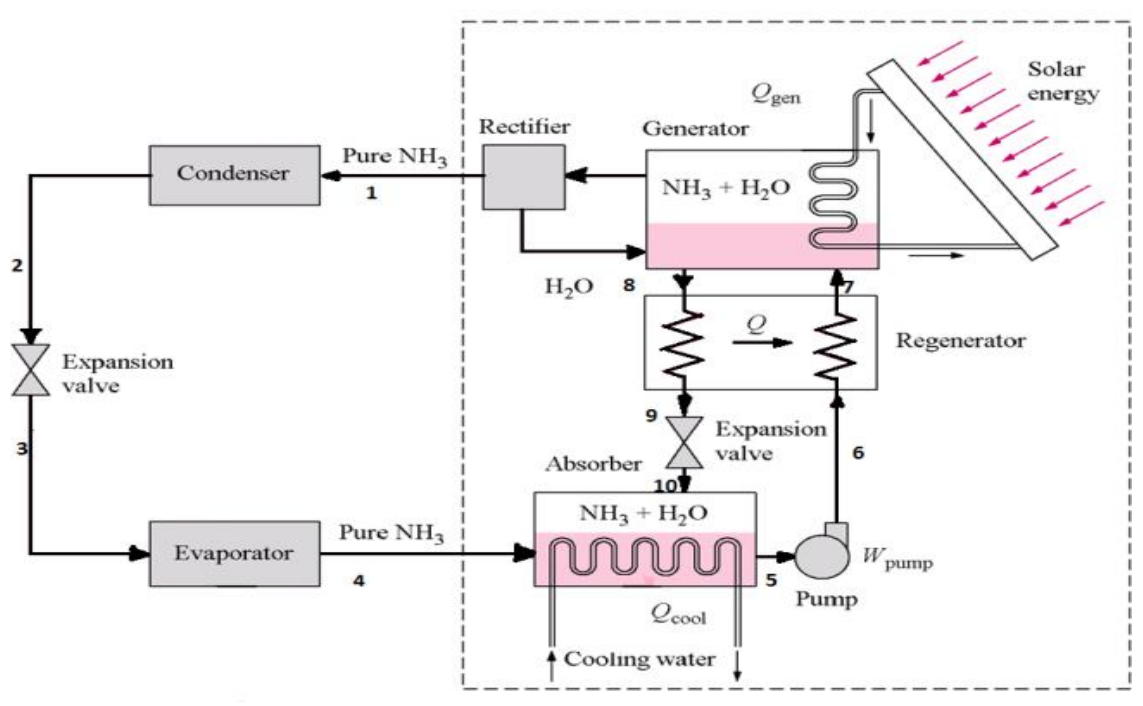

Fig.4: solar based vapour absorption refrigeration system: 


\section{Working principle of solar based vapour absorption refrigeration system:}

The main components of the solar absorption refrigeration system are solar thermal collector, an absorber, generator, a condenser, an expansion valve, a heat exchanger and a pump. Simple diagram of the solar absorption refrigeration system shown in Fig. 4. Two kinds of working medium are used at the same time in refrigeration and absorption processes.

In this system the solar thermal collector collect heat by absorbing sunlight. The heat collected in the solar collector transferred the generator which is used for heating an ammonia-water solution and send the vapour to the condenser. Remaining weak solution flows to the absorber through heat exchanger where the heat is transferred to the strong solution. Liquid refrigerant from the condenser goes through an expansion valve while the pressure is decreased to an effect is achieved by the vaporization of the refrigerant at a low temperature. Refrigerant vapor from the evaporator continues to an absorber and dissolves in a weak refrigerant solution, and it becomes a stronger refrigerant solution, which is called "rich solution". A pump is the only moving part in this system. The "rich solution" is pumped to a generator.

At the generator, the rich solution is heated up; the refrigerant is separated from the solution. The refrigerant is vaporized and goes to the condenser while the weak solution is passed through a heat exchanger and returned to the absorber to absorb the refrigerant vapour. The refrigeration process and the regeneration process operate at the same time as the continuous process, producing a continuous cooling effect. A flat plate solar collector can maintain the operating condition at the generation temperature.

\section{III.THERMODYNAMIC ANALYSIS:}

GENERATOR: On balancing the energy across the generator

Since:

$\mathrm{Qg}+\mathrm{Q}_{8}=\mathrm{Q}_{7}+\mathrm{Q}_{1}$

$\mathrm{Q}_{\mathrm{G}}=$ Generator heat

$\mathrm{Q}_{8}=\mathrm{m}_{8} \mathrm{~h}_{8}$
$\mathrm{Q}_{8}=$ Generator outlet heat

$\mathrm{M}_{8}=$ mass flow rate at point8 (weak solution)

$\mathrm{h}_{8}=$ enthalpy at point 8

$\mathrm{Q}_{7}=\mathrm{m}_{7} \mathrm{~h}_{7}$

$\mathrm{m}_{8}=$ mass flow rate at point7 (weak solution)

$\mathrm{Q}_{1}=\mathrm{m}_{1} \mathrm{~h}_{1}$

$\mathrm{Q}_{1}=$ generator outlet heat to the condenser

$\mathrm{m}_{1}=$ mass flow rate at point 1 (strong solution)

$\mathrm{h}_{1}=$ enthalpy of ammonia at inlet of condenser

$\mathrm{Q}_{\mathrm{G}}=\left(\mathrm{m}_{7} \mathrm{X} \mathrm{h_{7 }}\right)+\left(\mathrm{m}_{1} \mathrm{X} \mathrm{h_{7 }}\right)-\left(\mathrm{m}_{8} \mathrm{X} \mathrm{h} \mathrm{h}_{8}\right)$

CONDENSER: on balancing the energy across the condenser

$\mathrm{Q}_{\mathrm{C}}+\mathrm{Q}_{1}=\mathrm{Q}_{2}$

Since,

$\mathrm{Qc}=$ condenser heat

$\mathrm{Q}_{1}=\mathrm{m}_{1} \mathrm{~h}_{1}$

$\mathrm{Q}_{2}=\mathrm{m}_{2} \mathrm{~h}_{2}$

$\mathrm{m}_{2}=$ mass flow rate at point 2 


$$
\begin{aligned}
& \mathrm{h}_{2}=\text { enthalpy of ammonia at outlet of condenser } \\
& \mathrm{Qc}=\left(\mathrm{m}_{2} \mathrm{X} \mathrm{h}_{2}\right)-\left(\mathrm{m}_{1} \mathrm{X} \mathrm{h}_{1}\right)
\end{aligned}
$$

EVAPORATOR: On balancing the energy across the evaporator

$\mathrm{Q}_{\mathrm{E}}+\mathrm{Q}_{3}=\mathrm{Q}_{4}$

$\mathrm{Q}_{\mathrm{E}}=$ Evaporator heat

Since,

$$
\begin{aligned}
& \mathrm{Q}_{3}=\mathrm{m}_{3} \mathrm{~h}_{3} \\
& \mathrm{~m} 3=\text { mass flow rate at point } 3 \\
& \mathrm{~h}_{3}=\text { enthalpy of ammonia at throttle valve outlet } \\
& \mathrm{Q}_{4}=\mathrm{m}_{4} \mathrm{~h}_{4} \\
& \mathrm{~m}_{4}=\text { mass flow rate at point } 4 \\
& \mathrm{~h}_{4}=\text { enthalpy vapour ammonia at evaporator outlet } \\
& \mathrm{Q}_{\mathrm{E}}=\left(\mathrm{m}_{4} \mathrm{X} \mathrm{h}_{4}\right)-\left(\mathrm{m}_{3} \mathrm{X} \mathrm{h}_{3}\right)
\end{aligned}
$$

ABSORBER: on balancing the energy across the absorber

$$
\begin{aligned}
\mathrm{Q}_{\mathrm{A}}+\mathrm{Q}_{4}=\mathrm{Q}_{10}+\mathrm{Q}_{5} \\
\mathrm{Q}_{\mathrm{A}}=\text { absorber heat } \\
\mathrm{Q}_{4}=\mathrm{m}_{4} \mathrm{X} \mathrm{h}_{4} \\
\mathrm{Q}_{10}=\mathrm{m}_{10} \mathrm{X} \mathrm{\textrm {h } _ { 1 0 }} \\
\mathrm{m}_{10}=\text { mass flow rate at point } 10 \\
\mathrm{~h}_{10}=\text { enthalpy at point } 10 \\
\mathrm{Q}_{5}=\mathrm{m}_{5} \mathrm{X} \mathrm{h}_{5} \\
\mathrm{~m}_{5}=\text { mass flow rate at point } 5 \\
\mathrm{~h}_{5}=\text { enthalpy of weak mixture at absorber outlet }
\end{aligned}
$$

\section{1) Calculations for cop at ammonia concentration is 0.90}

Generator admit strong solution temperature $=82^{\circ} \mathrm{c}$

Generator temperature $=135^{\circ} \mathrm{c}$

Generator leaving temperature $=135^{\circ} \mathrm{c}$

Condenser temperature $=40^{\circ} \mathrm{c}$

Evaporator temperature $=20^{\circ} \mathrm{c}$

Absorber temperature $=40^{\circ} \mathrm{c}$

Pressure $(\mathrm{P})=15$ bar at generator and condenser

Pressure $(\mathrm{P})=5$ bar at throttle valve and evaporator

Mass of ammonia in condenser, throttle valve and evaporator $=1 \mathrm{~kg}$

Mass of weak solution in generator admit $(\mathrm{m})=\left(\mathrm{m}_{\mathrm{w}}+1\right) \mathrm{kg}$

Mass of weak solution at generator leaving $(\mathrm{m})=\mathrm{m}_{\mathrm{w}} \mathrm{kg}$

The strong solution concentration of pure ammonia vapour $=0.90$

The weak solution concentration of vapour mixture $=0.50$

The concentration of generator outlet for weak solution $=0.0833$

Energy balance

$$
\begin{gathered}
\mathrm{Q}_{\mathrm{G}}=\mathrm{Q}_{1}+\mathrm{Q}_{8}-\mathrm{Q}_{7} \\
\mathrm{Q}_{\mathrm{G}}=\left(\mathrm{m}_{1} \mathrm{xh}_{1}\right)+\left(\mathrm{m}_{8} \mathrm{xh}_{8}\right)-\left(\mathrm{m}_{7} \mathrm{xh}_{7}\right) \\
=(1 \times 1391.129791)+(1.2 \times 522.862161)-(2.2 \times 129.536485) \\
\mathrm{Q}_{\mathrm{G}}=1733.396857 \mathrm{~W} \\
\mathrm{Q}_{\mathrm{E}}=\left(\mathrm{m}_{4} \mathrm{xh}_{4}-\mathrm{m}_{3} \mathrm{xh}_{3}\right)
\end{gathered}
$$




$$
=0.90 \mathrm{x}(1314.516806-12.8523750)
$$

$$
\mathrm{Q}_{\mathrm{E}}=1301.664431 \mathrm{~W}
$$

$\mathrm{Cop}=\frac{\text { Net rerfigeration effect }}{\text { Heat to genpump work }}$

$\mathrm{Cop}=\frac{Q g}{Q g}$

Pump work can be neglected

$\mathrm{Cop}=\frac{1301,664431}{1733.396867}$

$\mathrm{Cop}=0.752$

\section{2) At ammonia concentration is 0.91}

Generator admit strong solution temperature $=82^{\circ} \mathrm{c}$

Generator temperature $=135^{\circ} \mathrm{c}$

Generator leaving temperature $=135^{\circ} \mathrm{c}$

Condenser temperature $=40^{\circ} \mathrm{c}$

Evaporator temperature $=20^{\circ} \mathrm{c}$

Absorber temperature $=40^{\circ} \mathrm{c}$

Pressure $(\mathrm{P})=15$ bar at generator and condenser

Pressure $(\mathrm{P})=5$ bar at throttle valve and evaporator

Mass of ammonia in condenser, throttle valve and evaporator $=1 \mathrm{~kg}$

Mass of weak solution in generator admit $(m)=\left(m_{w}+1\right) \mathrm{kg}$

Mass of weak solution at generator leaving $(\mathrm{m})=\mathrm{m}_{\mathrm{w}} \mathrm{kg}$

The strong solution concentration of pure ammonia vapour $=0.91$

The weak solution concentration of vapour mixture $=0.50$

The concentration of generator outlet for weak solution $=0.0762$

Energy balance

$$
\begin{aligned}
& \mathrm{Q}_{\mathrm{G}}=\mathrm{Q}_{1}+\mathrm{Q}_{8}-\mathrm{Q}_{7} \\
& \mathrm{Q}_{\mathrm{G}}=\left(\mathrm{m}_{1} \mathrm{xh}_{1}\right)+\left(\mathrm{m}_{8} \mathrm{xh}_{8}\right)-\left(\mathrm{m}_{7} \mathrm{xh}_{7}\right) \\
& \mathrm{Q}_{\mathrm{G}}=(1 \times 1390.183058)+(1.18 \times 524.965320)-(2.18 \times 129.536485) \\
& \mathrm{Q}_{\mathrm{G}}=1727.252598 \mathrm{~W} \\
& \mathrm{Q}_{\mathrm{E}}=\mathrm{m}(\mathrm{h} 4-\mathrm{h} 3) \\
& =1 \mathrm{x}(1313.807404-20.517621) \\
& \mathrm{Q}_{\mathrm{E}}=1293.29119 \mathrm{~W} \\
& \mathrm{Cop}=\frac{Q g}{Q g} \\
& =\frac{1293.29119}{1727,262598} \\
& \mathrm{Cop}=0.748
\end{aligned}
$$

\section{3) At ammonia concentration is $\mathbf{0 . 9 2}$}

The strong solution concentration of pure ammonia vapour $=0.92$

The weak solution concentration of vapour mixture $=0.50$

The concentration of generator outlet for weak solution $=0.0689$

$$
\mathrm{Q}_{\mathrm{G}}=\mathrm{Q}_{1}+\mathrm{Q}_{8}-\mathrm{Q}_{7}
$$




$$
\begin{aligned}
\mathrm{Q}_{\mathrm{G}}=\left(\mathrm{m}_{1} \mathrm{xh}_{1}\right) & +\left(\mathrm{m}_{8} \mathrm{xh}_{8}\right)-\left(\mathrm{m}_{7} \mathrm{xh}_{7}\right) \\
& =(1 \times 1389.202674)+(1.161 \times 529.017564)-(2.161 \times 129.536485) \\
& =1723.463766 \mathrm{~W} \\
\mathrm{Q}_{\mathrm{E}}=\mathrm{m}(\mathrm{h} 4-\mathrm{h} 3) & \\
\mathrm{Q}_{\mathrm{E}} & =1(1313.089366-28.272710) \\
& =1284.81662 \mathrm{~W} \\
\mathrm{Cop} & =\frac{1284.81662}{172.4663766} \\
\text { Cop } & =0.745
\end{aligned}
$$

Similarly the remaining values are obtained .

\section{IV.RESULTS AND DISCUSSION}

The results obtained by the theoretical work are shown in the graph

Variation of $\mathrm{COP}$ with ammonia concentration

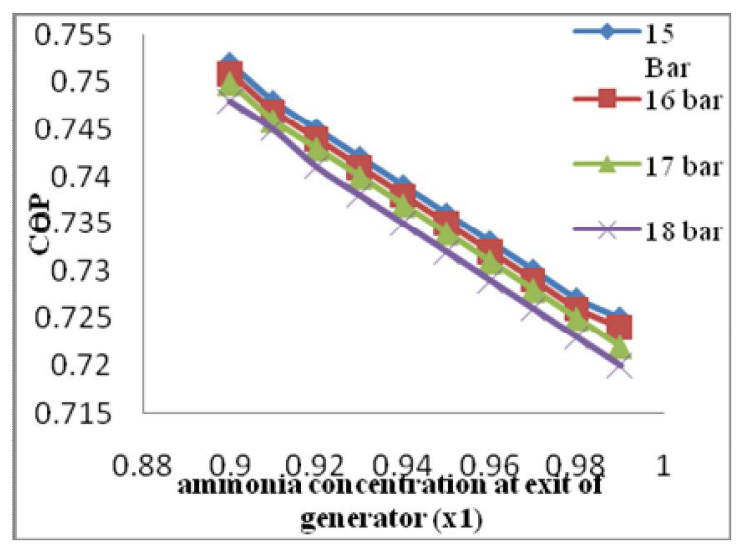

Variation of $\mathrm{COP}$ with pressure:

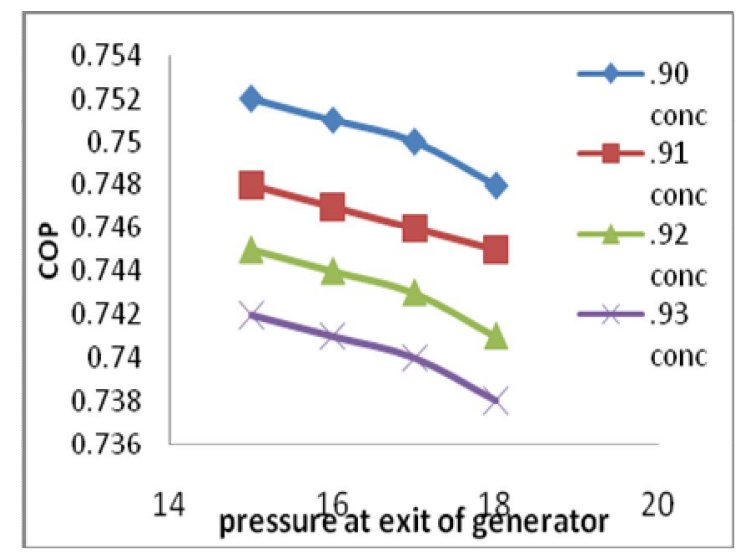

Fig.5 Cop vs concentration chart at different pressures Fig.6 Cop vs Pressure chart at different concentration

From Fig.5 above graph, by increasing the concentration of ammonia the cop of the cycle decreases slightly at constant pressure and temperature of generator. This is due to, as the concentration of ammonia at the generator outlet to the condenser is increasing, then it cause fall in concentration of weak solution to the absorber, as well as decrease the mass of weak solution. So that the enthalpy of strong ammonia solution is decreases, and increase in enthalpy of weak solution. Hence the generator heat is getting decreased.

As the concentration of strong solution to the inlet of the evaporator is increasing, then the enthalpy of saturated ammonia $\left(h_{1}\right)$ and the enthalpy of saturated vapour ammonia $\left(h_{g}\right)$ at the outlet of evaporator is getting decreased, due to this the heat removed capacity of the refrigerant in the evaporator is decreased that is " $\mathrm{Q}$ " is decreased. From the above cases the COP is decreasing as the concentration of ammonia increases.

From Fig.6 above graph, as the pressure at the generator is increasing, COP decreased, with concentration of ammonia kept at constant. This is due to, as the pressure at the generator outlet to the condenser is increasing, then it causes fall in concentration of weak solution to the absorber, as well as decrease the mass of weak solution. So that the enthalpy of strong ammonia solution is decreases, and increase in the enthalpy of weak solution. Hence the generator heat $\left(\mathrm{Q}_{\mathrm{g}}\right)$ is getting decreased. 
As the concentration of ammonia kept constant at the evaporator, then the enthalpy of saturated ammonia $\left(h_{l}\right)$ is increasing and the enthalpy of saturated vapour ammonia $\left(h_{g}\right)$ at the outlet of evaporator is getting decreased, due to this the heat absorbing capacity of the refrigerant in the evaporator is decreased that is " $\mathrm{Q}$ " is decreased.
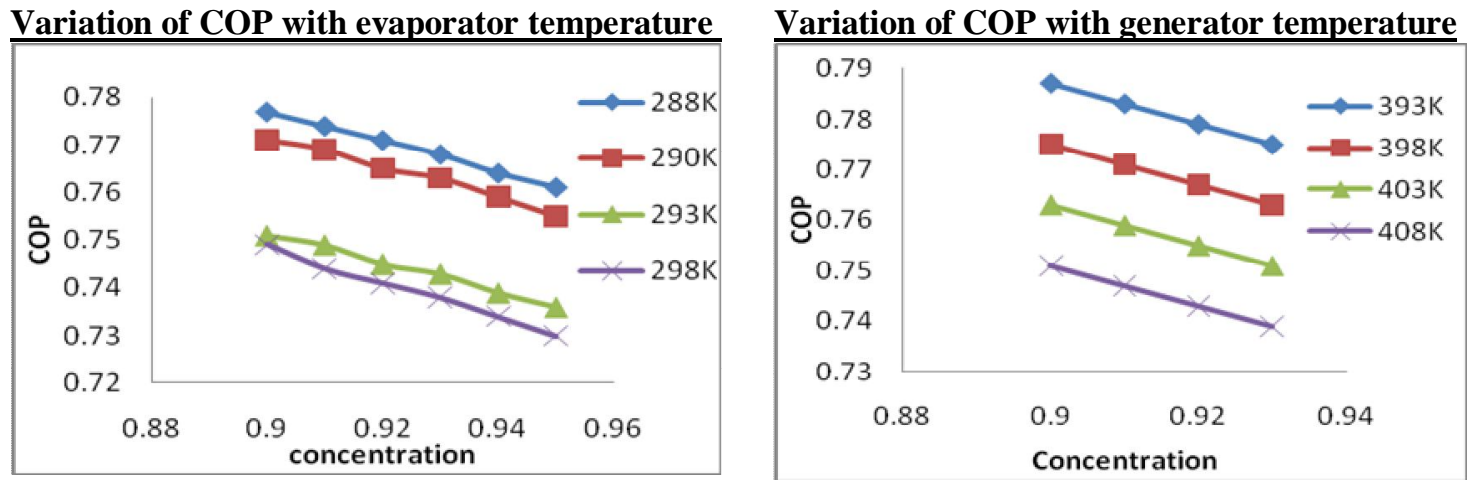

\section{Fig.7 Cop vs Concentration Graph at different evaporator pressure Fig.8 Cop vs Concentration Graph at different generator temperature}

From Fig.7 above graph gives the information about the COP variation along with the concentration at different evaporator pressure. When the generator temperature and pressures are fixed. Here we are observing the $\mathrm{COP}$ is decreasing continuously while increasing the concentration. And increasing the evaporator pressures the COP values are increasing. why because the latent heat of vapour is increasing

From Fig.8 the above graph say the COP is varying along with the concentration at different generator temperatures. Here we are observing the COP values are decreasing continuously while increasing the concentration. When the generator temperature is increases the COP values are decreasing why because the heat input to the generator is increases and heat absorbing capacity of the evaporator is kept at constant so therefore the COP are decreases

\section{V.CONCLUSION}

Thermodynamic analysis of solar based vapour absorption refrigeration cycle is done. The performance of the cycle has been studied at the different concentration of ammonia. The generator outlet concentration is varied from 0.90-0.99 and the COP of the cycle obtained at constant pressure and temperature of generator. With the increase of ammonia concentration at generator outlet, COP of the cycle slightly decreases.

The pressure increases with concentration of ammonia kept at constant, the enthalpy at the generator increases resulting in increase in generator heat input. Hence as the pressure increases COP decreases.

\section{VI.FUTURE WORK}

The cycle can be optimized to increase the cop. The solar based vapour absorption refrigeration cycle using solar energy and kalina cycle using solar energy can be combined in such a way that two cycles run simultaneously and produce desire output. 


\section{REFERENCES}

[1] V.R.Rem Injithe and P.J. Joshy.Vapour absorption refrigeration system using low grade energy- an Ecofriendly Apporoach. 1995.

[2] Shaoguang Lu and D.Yogi Goswami. Theoritical analysis of ammonia-based combined power / refrigeration cycle at low refrigeration temperatures . 2002 Sunrise on the Reliable Economy June 15-20, Reno, Nevada.

[3] V. Mittal K..S. Kasanna and N.S. Thakur. The study of solar absorption air- conditioning systems. 2005 VOL.16,NO.4.

[4] Omer Kaynakli and Recep Yamankaradeniz. Thermodynamic analysis of absorption refrigeration system based on entropy generation. RESEARCH ARTICLES (25 Feb 2007) VOL.92,No.4.

[5] Satish Raghuvanshi, Govind Maheshwari. Analysis of Ammonia-Water (NH3-H2O) Vapor Absorption Refrigeration System based on First Law of Thermodynamics. IJSER 2022; VOL 2.

[6] Thermodynamics analysis of R134A- DMAC vapour absorption refrigeration (VAR) system. IJCER 2012 ;VOL 2 ;086-096.

[7] Patek J, Klomfar J (1995). "Simple functions for fast calculations of selected thermodynamic properties of the ammonia - water system ", Refrig 18:228-234.

[8] Barhoumi M, Snoussi A, Ben EN, Bellagi A (2004). Modeling of thermodynamic properties of the ammonia / water mixture . Int. J. Refrig,27;271-283.

[9] N. Shankar Ganesh and T. Srinivas 'Evaluation of thermodynamic properties of ammonia water mixture up to 100 bar for power application systems.

[10] Hasan Aa, Goswami DY. Exergy analysis of a combined power and refrigeration thermodynamic cycle driven by a solar heat source. ASME J Sol Energy Eng 2003:125(1);55-60.

[11] Rogdakis ED, Antonopoulos KA. A high efficiency NH3-H2O absoption power cycle, Heat Recov Syst CHP $1991 ; 11 ; 263-75$.

[12] Srinivas T, Gupta AVSSKS, Reddy BV. Performance simulation of combined cycle with Kalina bottoming cycle. Cogener Distrib Gener J 2008; 23(1) 6-20.

[13] Ziegler B, Trepp CH (1984). “Equation of State for ammonia - water mixtures' Refrig, 7 101-106. 